\title{
Population-based preconception carrier screening: how potential users from the general population view a test for 50 serious diseases
}

\author{
Mirjam Plantinga ${ }^{\star,}$, Erwin Birnie $^{1}$, Kristin M Abbott ${ }^{1}$, Richard J Sinke ${ }^{1}$, Anneke M Lucassen ${ }^{2}$, \\ Juliette Schuurmans ${ }^{1}$, Seyma Kaplan ${ }^{1}$, Marian A Verkerk ${ }^{3}$, Adelita V Ranchor ${ }^{4}$ and Irene M van Langen ${ }^{1}$
}

\begin{abstract}
With the increased international focus on personalized health care and preventive medicine, next-generation sequencing (NGS) has substantially expanded the options for carrier screening of serious, recessively inherited diseases. NGS screening tests not only offer reproductive options not previously available to couples, but they may also ultimately reduce the number of children born with devastating disorders. To date, preconception carrier screening (PCS) has largely targeted single diseases such as cystic fibrosis, but NGS allows the testing of many genes or diseases simultaneously. We have developed an expanded NGS PCS test for couples; simultaneously it covers $\mathbf{5 0}$ very serious, early-onset, autosomal recessive diseases that are untreatable. This is the first, noncommercial, population-based, expanded PCS test to be offered prospectively to couples in a health-care setting in Europe. So far, little is known about how potential users view such a PCS test. We therefore performed an online survey in 2014 among 500 people from the target population in the Netherlands. We enquired about their intention to take an expanded PCS test if one was offered, and through which provider they would like to see it offered. One-third of the respondents said they would take such a test were it to be offered. The majority (44\%) preferred the test to be offered via their general practitioner (GP) and $58 \%$ would be willing to pay for the test, with a median cost of $€ 75$. Our next step is to perform an implementation study in which this PCS test will be provided via selected GPs in the Northern Netherlands.
\end{abstract}

European Journal of Human Genetics (2016) 24, 1417-1423; doi:10.1038/ejhg.2016.43; published online 11 May 2016

\section{INTRODUCTION}

Preconception carrier screening (PCS) can detect whether a particular couple has an increased risk of having a child with a certain monogenic disease by testing the DNA of both partners to see whether they are (asymptomatic) carriers of such a condition. Serious autosomal recessive (AR) conditions with early onset impose a heavy physical and psychological burden on the affected child and his or her parents and are associated with high health-care costs. Such serious AR conditions account for $\sim 20 \%$ of infant mortality and $10 \%$ of pediatric hospitalizations. ${ }^{1,2}$

As information regarding carrier status is usually not available in a family beforehand, the birth of a child with a serious AR condition usually arises unexpectedly. Population-based PCS, irrespective of family history or maternal age, can identify carrier couples so that they can take this information into account in their family planning. The key aim of offering a PCS test therefore is to increase reproductive autonomy, although reduction of health-care costs might well be a secondary result. As these reproductive choices can be made before the onset of pregnancy, couples are faced with fewer time constraints and less emotional stress compared with testing during pregnancy. ${ }^{3,4}$ Moreover, couples who learn about their risks before conception have more reproductive options available to them than those whose risk is detected during pregnancy or after the birth of an affected child and they have more time to discuss these options. ${ }^{5}$ Carrier couples could, for example, choose to make use of IVF with embryo selection (PGD) or prenatal diagnostics. ${ }^{6,7}$ Other options include the use of a gamete donor, adoption or refraining from having children with this partner. ${ }^{8}$

To date, PCS offered in European health-care systems usually tests for one or a few conditions based on ancestry, such as Ashkenazi Jewish founder variants, like Tay Sachs disease, ${ }^{9,10}$ and diseases with a high prevalence in European populations, like cystic fibrosis (CF). ${ }^{6,11,12}$ The recent introduction of next-generation sequencing (NGS) has allowed the screening of many genes or conditions simultaneously, ${ }^{8,13,14}$ and the costs of this type of screening are decreasing rapidly. ${ }^{12,15}$ This development has made it possible not only to offer PCS to high-risk groups, but also to screen the general population for a broad spectrum of conditions.

Such general population testing for several conditions simultaneously has not yet been offered within a health-care setting in Europe. There are commercial screening tests, such as the American Counsyl test ${ }^{16}$ that is available online and offered in Europe via the Belgium firm Gendia. These commercial tests do not distinguish between serious and mild conditions, or between early-onset and late-onset conditions, so that arguably their clinical utility and relevance in reproductive planning are less clear. ${ }^{17-19}$ In addition, commercial tests are usually not offered preconception but during pregnancy that also reduces the available reproductive options. ${ }^{12}$ Finally, pre- and post-test counselling is not always provided, so that

${ }^{1}$ Department of Genetics, University Medical Center Groningen, University of Groningen, Groningen, The Netherlands; ${ }^{2} \mathrm{Clinical}$ Ethics and Law, Faculty of Medicine, University of Southampton, Southampton, UK; ${ }^{3}$ Department of Internal Medicine, University Medical Center Groningen, University of Groningen, Groningen, The Netherlands; ${ }^{4}$ Department of Health Psychology, University Medical Center Groningen, University of Groningen, Groningen, The Netherlands

${ }^{*}$ Correspondence: Dr M Plantinga, Department of Genetics, University Medical Center Groningen, University of Groningen, CB50, P0 Box 30.001, 9700 RB Groningen, The Netherlands. Tel: +31 50 3617100; Fax: +31 50 3617230; E-mail: m.plantinga@umcg.nl

Received 29 October 2015; revised 17 February 2016; accepted 7 April 2016; published online 11 May 2016 
a core element of good clinical practice, reaching well-considered decisions, is not necessarily incorporated in the process. ${ }^{5}$

We developed an expanded NGS PCS test aimed at all couples wishing to have a child. It involves a blood sample ( $10 \mathrm{ml}$ per person) and screens for $\sim 70$ genes associated with some 50 very serious, untreatable, early-onset, AR diseases simultaneously. Disease severity was an important criterion for the composition of our panel. We included only those conditions that can be characterized as very serious, that is, early-onset conditions that involve severe mental and/or physical retardation, severe pain and/or premature death. Moreover, as the availability of treatment is regarded as an important characteristic in the classification of disease severity, ${ }^{20}$ we also chose to include only conditions that can be characterized as untreatable. For this reason, conditions included in the Dutch newborn screening programme and classified as treatable, such as CF, have not been included in our panel, despite them being serious and early onset. Based on our selection criteria, literature review ${ }^{2,8,13,20,21}$ and discussions with clinical geneticists, pediatricians, specialists in pediatric metabolic disorders and ethicists, we established a final first test panel (see Supplementary Materials).

The PCS test analysis has been validated in silico by the Department of Genetics' Genome Diagnostics section using whole genome sequencing data from the Genome of the Netherlands (GoNL). ${ }^{22}$ On the basis of the PCS gene list and both average allele frequencies and the PCS disease prevalence information, we used the HardyWeinberg equilibrium model to calculate a carrier risk of 1 in 150 for variants leading to the same serious disease per couple. Using the GoNL exome sequencing data set, an in silico proof-of-principle study was conducted to examine 100 randomly chosen males and 100 females, creating 100 randomly chosen couples. The variants associated with the genes included in the PCS panel were compared with the relevant 'damaging' variants in the Human Gene Mutation Database (HGMD). ${ }^{23}$ Other deleterious variants (premature loss or gain of termination codons, shifts in the reading frame and consensus splice site changes) not currently present in the HGMD were also examined. Of the 100 randomly paired couples tested for the proof-ofprinciple GoNL test, we found no carrier couples for a serious, recessively inherited disease, as could be expected with a carrier risk of 1 in 150 . We did find, on average, 0.69 frame shift/premature stop codon/splice site/HGMD variants per person. Although six individuals were found to carry variants within the same gene as their partner, these variants were not pathogenic in both, and hence the couples were not at risk of having children with the diseases associated with these genes. The couples were thus not deemed to be a carrier couple.

In contrast to other PCS tests, the current test is offered and analysed per couple and not per individual, meaning that each couple receives a result based on their combined genetic information. Important argument for offering couple results only is that a couple result provides prospective parents with information about their chance of having a child with a serious hereditary disease, whereas individual carrier results do not.

Diagnostic analysis parameters have been adjusted to ensure that only causal recessive variants are reported and that secondary findings not applicable to the couples' carrier status are avoided. Both known deleterious variants listed in the HGMD as well as other variants predicted to truncate and affect gene expression are considered and reported. Couples are considered as screen-positive only if diseaserelevant sequence variants are found in the same gene in both individuals, as only in this case is their risk of having a child with the associated disease increased.
The current PCS test will detect an increased risk in $\sim 1$ in 150 couples. Such a couple will have a 1 in $4(25 \%)$ chance per pregnancy of having a child affected by the condition that both the parents carry. Therefore, for each couple in the population, the average risk of conceiving a child with one of the conditions in our panel is 1 in 600 per pregnancy ( 1 in 150 times 1 in 4 ). This is higher than the birth prevalence of children with Down syndrome ( 1 in 1000) or CF ( 1 in 2500 to 1 in 3500) in Europe, ${ }^{6,24,25}$ conditions for which screening is widely accepted or even recommended.

We want to investigate whether responsible implementation of this population-based expanded NGS PCS test is desirable and feasible in Dutch health care. As a first step, we investigated in the current study potential users' intentions to undertake the test and through which provider they would like to see it offered.

\section{MATERIALS AND METHODS}

\section{Sample and target population}

Potential participants, both men and women with a partner and in the reproductive age, were recruited online by a survey research sampling company (Survey Sampling International, SSI; http://www.surveysampling.com) in March 2014. SSI panel participants were invited to participate in our survey and sampling was stratified according to gender, educational level and geographical region in order for the sample to be representative for the Dutch population. Only participants who met all our inclusion criteria, were aged 18-40 years, had a partner and were living in the Netherlands were given access to our online questionnaire. SSI panel participants were invited until 500 respondents were included. To award the time respondents invested in participating in the study, SSI offered an incentive (in reward points up to a maximum value of $€ 2.50$ ) to the respondents. Ethical clearance was granted by the Medical Ethical Review Committee of the University Medical Center Groningen (M14.152635).

\section{Survey design}

The survey was developed by a multidisciplinary research team and aimed to measure the intentions of potential users as well as their 'supply' preferences. An explorative qualitative interview study preceded the development of the survey. The qualitative interview study involved 20 potential users (11 female and 9 male, aged 18-28 years) and made use of a semistructured approach that was tested in a prepilot with 3 potential users. In the interviews we explored which factors influenced people's intention to participate in PCS and people's provider preferences. The interviews showed that the following factors were found to be of importance for people's intention: the opinion of partner, family and friends; fear for a positive test result; being familiar with hereditary diseases; people's attitude towards quality of life for future child and parents; the involvement of a professional; and the costs of the test. With regard to provider preferences, we found that it was considered important that information about the test was offered online and that information brochures were available and present at locations where people often go to when thinking about having children, such as general practitioners (GPs), hospitals and midwives. Finally, almost all respondents indicated wanting to discuss the option of testing with a professional during a personal encounter. The interview study provided us with important input for the development of our questionnaire, among others for the measurement of supply preferences for which no standardized measurements were available. For the measurement of intention we also made use of the Theory of Planned Behaviour Framework ${ }^{26}$ and previous research on CF screening. ${ }^{27,28}$

The survey started by providing respondents with (written) background information about population-based PCS. This outlined how everyone is likely to carry one or more AR variants that cause no problems or symptoms for that individual. However, if both partners carry such a variant in the same gene, the couple has a 1 in $4(25 \%)$ chance of an affected child in each pregnancy. Respondents were told that the PCS test would screen for a large set of very serious, early-onset diseases that cannot be treated. No information was given about the chances of being a 'carrier couple', because we wanted to assess 
respondents' perceived risk of this. The survey was created in Dutch using Unipark (www.unipark.de).

\section{Measures}

Intentions for population-based PCS. Potential users' intentions to take up population-based PCS were measured by two items: whether they intended to take up the current PCS test and their interest in other forms of populationbased PCS. Intention was measured according to the Theory of Planned Behaviour framework. ${ }^{26}$ The intention to take up the PCS test, if it were offered, was measured with one item (if this preconception carrier screening test were to be offered, I would be willing to participate) and rated on a 7-point Likert scale with anchors likely (1) and unlikely (7). The scores were categorized as 'likely' (scores 1-2), 'undecided' (3-5) and 'unlikely' (6-7).

In addition, we presented the respondents with 8 arguments in favour and 10 arguments against taking a PCS test and asked respondents what they perceived as most important. The arguments were developed within our multidisciplinary research team and tried to address a wide variety of possible (ethical) pro and contra arguments for PCS testing. Examples of pro arguments were 'I want to spare any child a life with a serious hereditary disease' and 'I want to be able to prepare myself for having a child with a serious hereditary disease', whereas contra arguments included 'I do not want to know if my partner and I are carriers' and 'I am against the selection of children by genetic screening' (see Table 2).

Finally, we wanted to reach a better understanding of the spectrum of conditions respondents would like to be screened for, in addition to the untreatable and early-onset diseases specified in our test. We drew up new items to measure their interest in different types of PCS tests. We asked respondents to rate their interest in four types of PCS tests: the current test screening for very serious, early-onset, untreatable conditions; a test screening for very serious, but to some extent treatable conditions; a test screening for very serious conditions that have an onset later in life; and a test screening for nonhealth-related predispositions for athletic ability or musicality, for example. Respondents were asked to indicate how much they would be interested in these different forms of population-based PCS tests on a 5-point Likert scale with anchors interested (1) and not interested (5). The scores were reduced to 'interested' (score 1, 2), 'neutral' (3) and 'not-interested' $(4,5)$.

\section{Preferences on the provision of the PCS test}

We measured respondents' preferences regarding the provision of the PCS test with the following newly constructed items. We asked respondents: (1) whether they have objections to provision of the PCS test to couples only; (2) to indicate their preferred provider from a list of possible providers (eg, GP, gynaecologist, pharmacist, direct to consumer); (3) to indicate from a list how they would like to be informed about the PCS test (general information (via brochure or website) or individual information (via e-mail, telephone or face-to-face in a pre-test counselling session); and (4) whether they would be willing to pay for the PCS test, and if so, the maximum amount they would be willing to pay.

\section{Data analysis}

Analyses were performed using IBM SPSS version 22 (IBM Corp., Armonk, NY, USA). Descriptive analyses were used to describe the sociodemographic characteristics of the respondents, their intentions for taking up the PCS test and their provider preferences. Educational level was categorized, in accordance with the classification of Statistics Netherlands, as: 'low' (finished primary school, lower secondary school or vocational training); 'intermediate' (higher level secondary school or intermediate vocational training); and 'high' (higher vocational training or university). Age was divided into three groups: 18-24, 25-32 and 33-40 years. Fisher's exact tests were used to compare nominal or ordinal response patterns between the different sociodemographic groups (Table 1).

\section{RESULTS}

Respondent characteristics

In our study, 869 individuals met the inclusion criteria and received access to our questionnaire. Of these, 504 (58\%) respondents completed the survey. There were no differences seen in gender when comparing dropouts with respondents. Dropouts were, however, a little older (average and median age of 31 years compared with an average age of 29 years and a median age of 28 years for respondents) and less often planned to have children (59\% compared with $70 \%$ for respondents). Respondents' characteristics are presented in Table 1. Of the 504 respondents, $72 \%$ were female. The mean age was 29

Table 1 Sociodemographic characteristics of respondents by intention group

\begin{tabular}{|c|c|c|c|c|c|}
\hline & All, 504 (100\%) & Unlikely, 74 (100\%) & Undecided, 257 (100\%) & Likely, 171 (100\%) & $P$-value \\
\hline Gender & & & & & 0.099 \\
\hline Female & $364(72 \%)$ & $49(66 \%)$ & $180(70 \%)$ & $133(78 \%)$ & \\
\hline Male & $140(28 \%)$ & 25 (34\%) & $77(30 \%)$ & $38(22 \%)$ & \\
\hline Age (in years) & & & & & 0.040 \\
\hline $18-24$ & $161(32 \%)$ & $18(24 \%)$ & $98(38 \%)$ & $44(26 \%)$ & \\
\hline 25-32 & $177(35 \%)$ & $27(37 \%)$ & $85(33 \%)$ & $65(38 \%)$ & \\
\hline $33-40$ & $166(33 \%)$ & 29 (39\%) & $74(29 \%)$ & $62(36 \%)$ & \\
\hline Educational level & & & & & 0.601 \\
\hline Low & $63(13 \%)$ & $12(16 \%)$ & $32(12 \%)$ & $18(10 \%)$ & \\
\hline Intermediate & 269 (53\%) & $36(49 \%)$ & $143(56 \%)$ & $90(53 \%)$ & \\
\hline High & 172 (34\%) & $26(35 \%)$ & $82(32 \%)$ & $63(37 \%)$ & \\
\hline Marital status (duration of relationship) & & & & & 0.349 \\
\hline Not living together ( 2 months-9.5 years) & $104(21 \%)$ & $16(22 \%)$ & $55(21 \%)$ & $33(19 \%)$ & \\
\hline Living together (7 months-11 years) & $234(46 \%)$ & $27(36 \%)$ & $124(48 \%)$ & $82(48 \%)$ & \\
\hline Married/registered partners (18 months-25 years) & $166(33 \%)$ & $31(42 \%)$ & $78(30 \%)$ & $56(33 \%)$ & \\
\hline Religion & & & & & $<0.001$ \\
\hline No & $329(65 \%)$ & $30(40 \%)$ & $175(68 \%)$ & $123(72 \%)$ & \\
\hline Yes & $175(35 \%)$ & $44(60 \%)$ & $82(32 \%)$ & $48(28 \%)$ & \\
\hline Wish to have child & & & & & 0.080 \\
\hline Yes & $351(70 \%)$ & $44(59 \%)$ & $182(71 \%)$ & $124(73 \%)$ & \\
\hline No & $126(25 \%)$ & 27 (37\%) & $57(22 \%)$ & 41 (24\%) & \\
\hline Already pregnant & $27(5 \%)$ & $3(4 \%)$ & $18(7 \%)$ & $6(3 \%)$ & \\
\hline
\end{tabular}


(SD 6.19) years and the median age was 28 years. Of the participants, $34 \%$ had a high education level, 53\% an intermediate level and 13\% a lower level. Relationship durations ranged from 2 months to 25 years. The majority of the respondents $(65 \%)$ were not religious. Finally, $70 \%$ of the respondents expressed the desire to have children with their current partner, $25 \%$ did not wish to have a child and 5\% were already pregnant.

\section{Respondents' intention to undertake PCS}

With regard to respondents' intention to undertake PCS, we find that $34 \%$ would take the test if it were offered, $15 \%$ would be unlikely to take the test and 51\% were still undecided. In Table 1, the response patterns between the different sociodemographic groups are presented per intention group (unlikely, undecided, likely). Significant differences were observed for both age and religion. Especially, young people reported more often to be undecided about testing: the proportion of young people was significantly higher in the 'undecided' group than the other intention groups. We also found that significantly more religious respondents were in the 'unlikely' group, indicating an inverse relationship between religion and intention to take the test.

We further asked about their arguments pro and contra PCS testing. Table 2 displays which of the 8 presented pro and 10 presented contra arguments for PCS testing are perceived as being most important. For the sample as whole, the argument that people want to spare their child a life with a serious hereditary disease is the pro argument mentioned most often by respondents (39\%) as being most important. Being able to prepare for having a child with a serious hereditary disease was the second most important pro argument, mentioned by $14 \%$, and avoiding abortion was brought forward by $10 \%$. The most important contra argument (for 23\% of respondents) was that respondents just did not want to be bothered by knowing whether they were an at-risk couple, whereas $13 \%$ said they were afraid that being a carrier would have consequences for their relationship, and $12 \%$ were against selection of children by screening.

Table 2 also displays per intention group which pro and contra arguments were perceived as most important. The most often selected pro argument, namely to spare their child a life with serious hereditary disease, was put forward particularly by those who were likely to take the test or undecided (45\% and $41 \%$ versus $23 \%$ for the unlikely intention group). The intention groups also differed with regard to some of the contra arguments they perceived as being most important. In the 'unlikely' group, $38 \%$ said their most important contra argument was that they were against selecting children by screening (against $4 \%$ in the likely group). In contrast, in the 'likely' group, 16\% said the most important contra argument was being afraid that finding out being a carrier couple might have consequences for their relationship (against 1\% in the unlikely intention group).

We finally measured the interest for other diseases and predispositions to be included in a PCS test. Figure 1 shows that respondents' interest in the different PCS tests was very similar, except for screening for nonhealth-related predispositions. Of all the respondents, 56\% were interested in the current PCS test for serious, untreatable and earlyonset disorders, $55 \%$ were interested in tests that screen for very serious but to some extent treatable conditions and $54 \%$ were interested in tests that screen for late-onset conditions. In addition, $19 \%$ were interested in tests that screen for nonhealth-related predispositions.

\section{Preferences on the provision of the PCS test}

With regard to providing the PCS test, we first asked whether

Table 2 Most important pro and contra arguments for taking a PCS test

\begin{tabular}{|c|c|c|c|c|}
\hline Arguments pro testing & $\begin{array}{l}\text { All, } 504 \\
(100 \%)\end{array}$ & $\begin{array}{l}\text { Unlikely, } 74 \\
\text { (100\%) }\end{array}$ & $\begin{array}{l}\text { Undecided, } 257 \\
\qquad(100 \%)\end{array}$ & $\begin{array}{l}\text { Likely, } 171 \\
\text { (100\%) }\end{array}$ \\
\hline I think that my partner and I as (future) parents have a responsibility to do this test. & $49(10 \%)$ & $6(8 \%)$ & $20(8 \%)$ & $22(13 \%)$ \\
\hline I want to spare our child a life with a severe hereditary disease. & 199 (39\%) & $17(23 \%)$ & $104(41 \%)$ & $77(45 \%)$ \\
\hline Carrier testing is socially expected from me and my partner. & $14(3 \%)$ & $1(1 \%)$ & $12(5 \%)$ & $1(1 \%)$ \\
\hline If the test shows that we together are not carriers, this would be a great relief. & $35(7 \%)$ & $4(6 \%)$ & $21(8 \%)$ & $10(6 \%)$ \\
\hline I want to prevent my partner and I having to take care of a child with a severe hereditary disease. & $32(6 \%)$ & $1(1 \%)$ & $16(6 \%)$ & $15(9 \%)$ \\
\hline $\begin{array}{l}\text { I want to know in good time if our child is at risk so as not to be confronted by having to make a } \\
\text { choice about a late abortion. }\end{array}$ & $44(9 \%)$ & $5(7 \%)$ & $18(7 \%)$ & $21(12 \%)$ \\
\hline I want to be able to prepare myself for having a child with a severe hereditary disease. & $71(14 \%)$ & $21(28 \%)$ & $37(14 \%)$ & $13(7 \%)$ \\
\hline I think that abortion should be prevented if possible. & $50(10 \%)$ & $17(23 \%)$ & $24(9 \%)$ & $9(5 \%)$ \\
\hline $\begin{array}{l}\text { Other pro arguments (eg, we are not capable of taking care of a child with a severe hereditary } \\
\text { disease). }\end{array}$ & $10(2 \%)$ & $2(3 \%)$ & $5(2 \%)$ & $3(2 \%)$ \\
\hline \multicolumn{5}{|l|}{ Arguments contra testing } \\
\hline I do not want to know if my partner and I are carriersmacmac & $114(23 \%)$ & $22(30 \%)$ & $66(26 \%)$ & $26(15 \%)$ \\
\hline I am against selecting children by screening (such as in this test). & $63(12 \%)$ & $28(38 \%)$ & $28(11 \%)$ & $7(4 \%)$ \\
\hline I am afraid that if we turn out to be carriers this will have consequences for my relationship. & $65(13 \%)$ & $1(1 \%)$ & $36(14 \%)$ & $27(16 \%)$ \\
\hline I am afraid that if we turn out to be carriers this will have consequences for my insurance policies. & $23(5 \%)$ & $1(1 \%)$ & $11(4 \%)$ & $11(6 \%)$ \\
\hline I am afraid that if we turn out to be carriers we will be regarded as people with a disease. & $18(4 \%)$ & $1(1 \%)$ & $11(4 \%)$ & $6(4 \%)$ \\
\hline I am afraid that if we turn out to be carriers this will be registered with the authorities. & $20(4 \%)$ & $1(1 \%)$ & $7(3 \%)$ & $11(6 \%)$ \\
\hline I am afraid that if we turn out to be carriers we will end up in a medical treadmill. & $49(10 \%)$ & $2(3 \%)$ & $24(9 \%)$ & $23(13 \%)$ \\
\hline The test result will have no influence on my having children with my partner. & $56(11 \%)$ & $9(12 \%)$ & $23(9 \%)$ & $24(14 \%)$ \\
\hline A test would take away the romance of a pregnancy. & $22(4 \%)$ & $1(1 \%)$ & $15(6 \%)$ & $6(4 \%)$ \\
\hline By taking a test, becoming pregnant is no longer natural. & $27(5 \%)$ & $4(6 \%)$ & 17 (7\%) & $6(4 \%)$ \\
\hline Other contra arguments (eg, if my partner does not want to be tested). & $47(9 \%)$ & $4(6 \%)$ & $19(7 \%)$ & $24(14 \%)$ \\
\hline
\end{tabular}




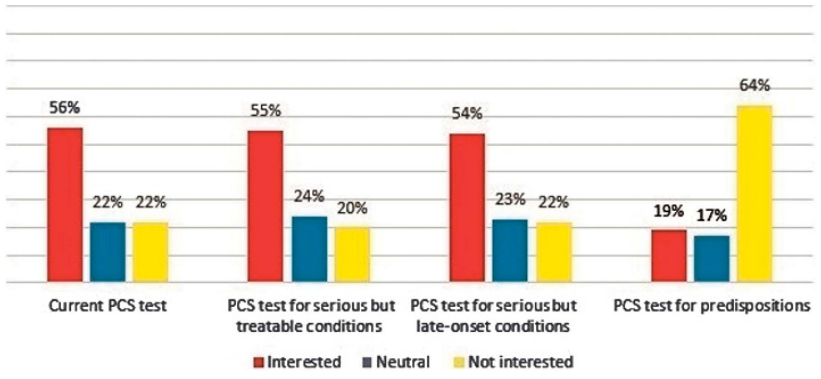

Figure 1 Interest in differently composed population-based PCS tests.

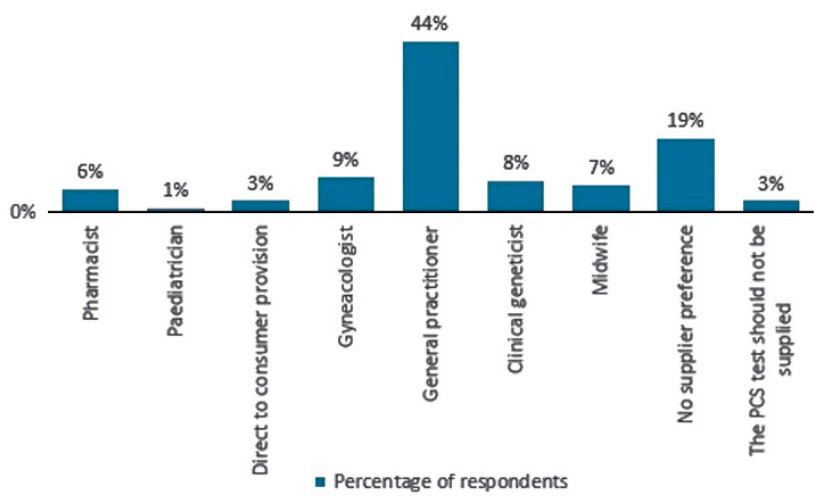

Figure 2 Preferences for different providers of the PCS test.

respondents object to provision of the test to couples only and not on individual basis. The majority (70\%) did not object to the provision of a couple-based test, 15\% did object and 15\% were undecided. We then asked respondents to indicate which provider they preferred from a list of possible providers. Their preferences are shown in Figure 2. The majority (44\%) preferred the PCS test to be offered via the GP and this preference was not related to respondents' intentions. There was no clear, second-best alternative. Almost 20\% did not state a preference at all and only $3 \%$ showed an interest in a direct-toconsumer test.

We also enquired about preferences for information about the PCS test and whether respondents would prefer a consultation with a health-care professional via e-mail, telephone or face-to-face counselling. Figure 3 shows that most respondents prefer individualised information via face-to-face consultation: $37 \%$ preferred this information route. General information by means of a brochure was also regarded as important and was the preferred option for $21 \%$ of respondents; $15 \%$ stated no preference.

Finally, we asked whether respondents would be willing to pay for the PCS test, and if so, what their maximum amount would be. Of those who said they would likely take the test if it was offered, 58\% would be willing to pay for it. The maximum amount ranged from $€ 5$ up to $€ 5000$, with a median amount of $€ 75$.

\section{DISCUSSION}

We have developed an NGS PCS test aimed at couples who want to have children: it simultaneously covers $\sim 70$ genes associated with some 50 very serious, early-onset and untreatable AR diseases (see Supplementary Materials). This is the first noncommercial, population-based PCS test to be offered to prospective couples in a health-care setting in Europe. Our results,

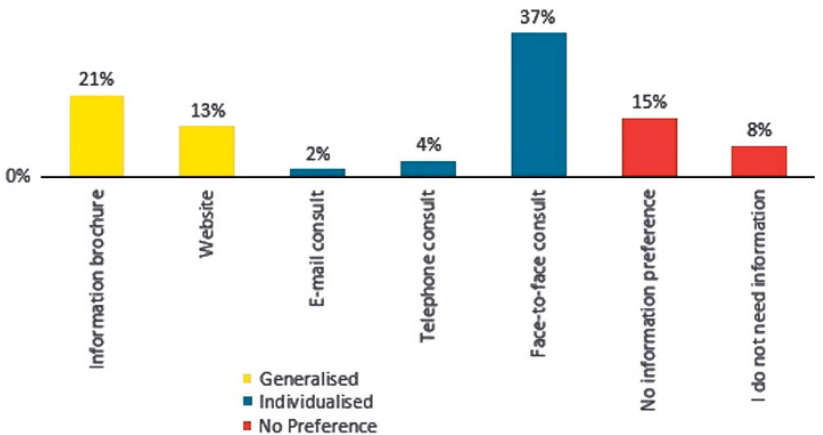

Figure 3 Preferences for different forms of information about the PCS test.

therefore, present a first glimpse of how potential users view such a PCS test.

Our study reveals a clear positive attitude towards this form of population-based PCS: more than half $(56 \%)$ of the respondents were interested in the test and one-third said they intended to take the test if it were offered. A minority (15\%) were unlikely to take the test, but many respondents $(51 \%)$ were still undecided after receiving this first information about the PCS test. A higher proportion of younger respondents were undecided. Respondents also reported an interest in testing for serious but later-onset diseases and in diseases that are to some extent treatable. There was less interest in testing for nonhealth-related predispositions (eg, athletic ability), although almost $20 \%$ were interested in such testing. Different arguments pro and contra testing were reported. The most important pro argument (for 39\% of the respondents) was to be able to spare a child a life with a serious hereditary disease, followed by being able to prepare for having a child with a serious hereditary disease (14\%). Remarkably, the pro argument of sparing oneself of having to take care of a severely affected child was mentioned far less often $(6 \%)$. The contra argument perceived as most important was that people did not want to be bothered by the knowledge of being a carrier couple. The arguments pro and contra varied slightly between the groups intending to undertake the test or not. Those who were unlikely to take the test were more against screening and against abortion, whereas those who were likely to take the test had more diverse arguments that were often related to their relationship. Finally, we found that the GP was the preferred provider of the PCS test. Given the Dutch health-care context, which has a strong primary care structure $^{29}$ and in which healthy young women are not regularly seen by a gynaecologist but primarily by their GP (who plays an important role as a gatekeeper), this preference is perhaps not surprising.

The sample of 500 respondents was chosen to represent Dutch potential users of the PCS test. Although the sample selection was performed with great care, we do not know how representative our sample was for Dutch users of the PCS test. Female respondents were overrepresented that may have influenced our findings, although we observed no differences between the sexes. Furthermore, nonresponse bias is difficult to assess in online samples. People who do not have access to the internet are excluded, for example, and only those who choose to join a research panel can be included. Furthermore, response rates for samples can be accurately reported when the sampling frame is known in advance. However, in internet surveys the sampling frame is often unknown in advance and response rates become meaningless. ${ }^{30}$ The best parameter that can be provided 
is a 'participant rate' that was $58 \%$ is our study. Despite the sampling problems, we believe they give a good indication of the views of potential Dutch users of the PCS test. Further research will be necessary to validate our results and to investigate intentions and provider preferences in other populations with different healthcare systems.

As our test will be the first noncommercial, population-based, expanded PCS test to be offered prospectively to couples in a healthcare setting in Europe, little was known about how potential users would view such a test and how our results would relate to other research. The differences we found in arguments pro and contra between different intention groups relate to results from Schneider et al, ${ }^{31}$ who recently explored preconception genomic carrier screening in a focus group study and found that people displaying a 'certain' versus a 'hesitant' orientation towards preconception genomic carrier screening, demonstrate differences in perceived advantages or disadvantages of screening. Moreover, extensive research results are available regarding the offer of PCS tests for single AR conditions, especially on testing for CF. This research has shown that $54-80 \%$ of the general population is interested in carrier screening for CF: $3256 \%$ would take the test, $27 \%$ were undecided and $17 \%$ would not be willing to participate. $^{28}$ Important reasons for participating in CF screening were to avoid having a child with $\mathrm{CF}$ and to prepare for a child with CF, whereas the main reasons for not participating included lack of time and not wanting to know the test results. ${ }^{33}$ Finally, the GP was in the CF research also found the preferred delivery route. ${ }^{32,34}$

Given that prospective users in both our research and the research on CF had a positive attitude towards the potential implementation of an expanded carrier test, we have decided to proceed to the next step that is to start an implementation study with the test being offered to couples from the general population. Our findings have provided important input for the design of such an implementation study. Our goal will be to investigate whether our PCS test can be implemented responsibly via GPs as part of preconception care for couples wishing to have a child. The responsible implementation of the test will be evaluated by studying the psychological impact, uptake and practical feasibility.

An expanded PCS test for the general population that screens for several conditions simultaneously is currently not being offered within a health-care setting in Europe. As a result, a child born with a serious AR condition is not anticipated in most cases. With the offer of population-based PCS, carrier couples can be identified preconception and they can then incorporate this information in their family planning. Our NGS PCS test is aimed at all couples wishing to have a child; simultaneously it covers $\sim 70$ genes associated with some 50 very serious, AR diseases. One-third of our respondents said they would take this test if it were offered. They would prefer it to be offered via their GP and after face-to-face pretest consultation. Many would be willing to pay for the test (58\%) with a median cost of $€ 75$. These findings have been incorporated into our study to investigate whether responsible implementation of population-based expanded carrier screening in health care is possible and desirable.

\section{CONFLICT OF INTEREST}

The authors declare no conflict of interest.

\section{ACKNOWLEDGEMENTS}

We thank Anne Buitenhuis for help with data collection, Jackie Senior for editing the manuscript and the Department of Genetics for financial support (Charles Buijs grant).
1 Srinivasan BS, Evans EA, Flannick J et al: A universal carrier test for the long tail of Mendelian disease. Reprod Biomed Online 2010; 21: 537-551.

2 Bell CJ, Dinwiddie DL, Miller NA et al: Carrier testing for severe childhood recessive diseases by next-generation sequencing. Sci Transl Med 2011; 3: $65 \mathrm{ra4}$.

3 Bombard Y, Miller FA, Hayeems RZ, Avard D, Knoppers BM: Reconsidering reproductive benefit through newborn screening: a systematic review of guidelines on preconception, prenatal and newborn screening. Eur J Hum Genet 2010; 18: 751-760.

4 De Wert GM, Dondorp WJ, Knoppers BM: Preconception care and genetic risk: ethical issues. J Community Genet 2012; 3: 221-228.

5 Godard B, ten Kate L, Evers-Kiebooms G, Ayme S: Population genetic screening programmes: principles, techniques, practices, and policies. Eur J Hum Genet 2003; 11 Suppl 2: S49-S87.

6 Janssens S, Chokoshvilli D, Binst C et al: Attitudes of cystic fibrosis patients and parents toward carrier screening and related reproductive issues. Eur J Hum Genet 2015; 11 (Suppl 2): S49-S87.

7 Castellani C, Macek Jr M, Cassiman JJ et al: Benchmarks for cystic fibrosis carrier screening: a European consensus document. J Cyst Fibros 2010; 9: $165-178$.

8 Inthorn J: Fuzzy logic and preconceptional genetic carrier screening. APHSC 2014; 1 : $1-10$.

9 Grinzaid KA, Page PZ, Denton JJ, Ginsberg J: Creation of a National, at-home model for Ashkenazi Jewish carrier screening. J Genet Couns 2015; 24: 381-387.

10 Nazareth SB, Lazarin GA, Goldberg JD: Changing trends in carrier screening for genetic disease in the United States. Prenat Diagn 2015; 35: 931-935.

11 Ioannou L, Massie J, Collins V, McClaren B, Delatycki MB: Population-based genetic screening for cystic fibrosis: attitudes and outcomes. Public Health Genomics 2010; 13: 449-456.

12 McGowan ML, Cho D, Sharp RR: The changing landscape of carrier screening: expanding technology and options? Health Matrix Clevel 2013; 23: 15-33.

13 Kingsmore S: Comprehensive carrier screening and molecular diagnostic testing for recessive childhood diseases. PLoS Curr 2012; 1: 1-23.

14 Edwards JG, Feldman G, Goldberg $J$ et al: Expanded carrier screening in reproductive medicine-points to consider: a joint statement of the American College of Medical Genetics and Genomics, American College of Obstetricians and Gynecologists, National Society of Genetic Counselors, Perinatal Quality Foundation, and Society for Maternal-Fetal Medicine. Obstet Gynecol 2015; 125: 653-662.

15 Hayden EC: Technology: The \$1,000 genome. Nature 2014; 507: 294-295.

16 Lazarin GA, Haque IS, Nazareth S et al: An empirical estimate of carrier frequencies for $400+$ causal Mendelian variants: results from an ethnically diverse clinical sample of 23,453 individuals. Genet Med 2013; 15: 178-186.

17 Borry P, Henneman L, Lakeman P, ten Kate LP, Cornel MC, Howard HC: Preconceptional genetic carrier testing and the commercial offer directly-to-consumers. Hum Reprod 2011; 26: 972-977.

18 Henneman L, Borry P, Chokoshvili D et al: Responsible implementation of expanded carrier screening. Eur J Hum Genet 2016; e-pub ahead of print 16 March 2016; doi:10.1038/ejhg.2015.271

19 Leo MC, McMullen C, Wilfond BS et al: Patients' ratings of genetic conditions validate a taxonomy to simplify decisions about preconception carrier screening via genome sequencing. Am J Med Genet A 2016; 170: 574-582.

20 Lazarin GA, Hawthorne F, Collins NS, Platt EA, Evans EA, Haque IS: Systematic classification of disease severity for evaluation of expanded carrier screening panels. PLoS One 2014; 9: e114391.

21 Grody WW, Thompson BH, Gregg AR et al: ACMG position statement on prenatal/ preconception expanded carrier screening. Genet Med 2013; 15: 482-483.

22 Francioli LC, Menelaou A, Pulit SL et al: Whole-genome sequence variation, population structure and demographic history of the Dutch population. Nat Genet 2014; 46: 818-825.

23 Stenson PD, Mort M, Ball EV, Shaw K, Phillips A, Cooper DN: The Human Gene Mutation Database: building a comprehensive mutation repository for clinical and molecular genetics, diagnostic testing and personalized genomic medicine. Hum Genet 2014; 133: 1-9.

24 Southern KW, Munck A, Pollitt R et al: A survey of newborn screening for cystic fibrosis in Europe. J Cyst Fibros 2007; 6: 57-65.

25 Loane M, Morris JK, Addor MC et al: Twenty-year trends in the prevalence of Down syndrome and other trisomies in Europe: impact of maternal age and prenatal screening. Eur J Hum Genet 2013; 21: 27-33.

26 Ajzen I: The theory of planned behavior. Organizational Behavior and Human Decision Processes. MIDSS 1991; 50: 179-211.

27 Henneman L, Bramsen I, van der Ploeg HM et al: Participation in preconceptional carrier couple screening: characteristics, attitudes, and knowledge of both partners. J Med Genet 2001; 38: 695-703.

28 Poppelaars FA, Henneman L, Ader $\mathrm{HJ}$ et al: Preconceptional cystic fibrosis carrier screening: attitudes and intentions of the target population. Genet Test 2004; 8 : 80-89.

29 Schafer WL, Boerma WG, Murante AM, Sixma HJ, Schellevis FG, Groenewegen PP: Assessing the potential for improvement of primary care in 34 countries: a crosssectional survey. Bull World Health Organ 2015; 93: 161-168.

30 Eysenbach G: Improving the quality of Web surveys: the Checklist for Reporting Results of Internet E-Surveys (CHERRIES). J Med Internet Res 2004; 6: e34. 
31 Schneider JL, Goddard KA, Davis J et al: 'Is it worth knowing?' Focus group participants' perceived utility of genomic preconception carrier screening. J Genet Couns 2015; 25: 135-145.

32 Ioannou L, McClaren BJ, Massie J et al: Population-based carrier screening for cystic fibrosis: a systematic review of 23 years of research. Genet Med 2014; 16: 207-216.

33 Henneman L, Bramsen I, van Kempen L et al: Offering preconceptional cystic fibrosis carrier couple screening in the absence of established preconceptional care services. Community Genet 2003; 6: 5-13.

34 Poppelaars FA, Henneman L, Ader HJ et al: How should preconceptional cystic fibrosis carrier screening be provided? Opinions of potential providers and the target population. Community Genet 2003; 6: 157-165. (c) (1) () $\odot$ This work is licensed under a Creative Commons Attribution-NonCommercial-NoDerivs 4.0 International

License. The images or other third party material in this article are included in the article's Creative Commons license, unless indicated otherwise in the credit line; if the material is not included under the Creative Commons license, users will need to obtain permission from the license holder to reproduce the material. To view a copy of this license, visit http://creativecommons.org/licenses/by-nc-nd/4.0/

Supplementary Information accompanies this paper on European Journal of Human Genetics website (http://www.nature.com/ejhg) 